\title{
Sardinian Language
}

National Cancer Institute

\section{Source}

National Cancer Institute. Sardinian Language. NCI Thesaurus. Code C154129.

An Indo-European Romance language spoken mainly on the island of Sardinia, Italy. 